Jefferson A. Alamani, Samantha S. Castaneda, ${ }^{1}$ Adrian F. Fernando ${ }^{1}$

'Department of OtorhinolaryngologyHead and Neck Surgery Jose R. Reyes Memorial Medical Center San Lazaro Compound, Rizal Avenue, Sta. Cruz, Manila

\title{
Reconstruction of a Large Through and Through Defect of the Oral Cavity Using a Double Anterolateral Thigh Free Flap
}

\begin{abstract}
Objectives: To present our application of a double anterolateral thigh (ALT) free flap in reconstruction of a large full thickness defect of the oral cavity, cheek and cervical area.
\end{abstract}

\section{Methods:}

\author{
Design: Case Report \\ Setting: Tertiary Government Hospital \\ Patient: One
}

Results: A 77-year-old male with a $20 \times 25 \mathrm{~cm}$ full thickness soft tissue defect on the facial and cervical area contiguous with a $6 \times 6 \mathrm{~cm}$ buccal defect resulting from wide tumor ablation of a Stage IVA (T4aN2bM0) squamous cell carcinoma of the buccal mucosa underwent reconstruction using two ALT free flaps. An ALT flap was designed to cover the intraoral and cheek defect while another ALT flap was used for external coverage of the cervical defect. The first ALT flap measured approximately $8 \times 22 \mathrm{~cm}$ while the second ALT flap measured $6 \times 21 \mathrm{~cm}$ harvested from the left and right thigh respectively. Temporary venous congestion was observed on the inferiorly placed ALT flap due to neck edema that spontaneously resolved on the second post-operative day. Minimal donor site complications observed were linear scars and a $1 \times 4 \mathrm{~cm}$ dehiscence on the right thigh that healed spontaneously by secondary intention.

Conclusion: The utilization of a double anterolateral thigh free flap allowed single-stage reconstruction of the large soft tissue head and neck defect with little donor site morbidity, shorter operating time and shorter hospital stay.

Keywords: anterolateral thigh free flap (ALT flap), double ALT flap, full-thickness buccal defect

Tumor ablation may be hampered when a reconstructive team is not available since head and neck surgeons performing tumor ablation may compromise the resection margins in consideration of subsequent closure of the defect especially in large and advanced-stage tumors. Microvascular surgery has broadened the options for available tissue to close large and complex head and neck defects. In response to such a challenge, we present our experience in reconstructing a large through-and-through defect of the buccal mucosa and cervical skin using a double anterolateral thigh free flap.

\section{CASE REPORT}

A 77-year-old man with a Stage IV-A (T4aN2bM0) moderately-differentiated squamous cell carcinoma of the left buccal mucosa that involved the lip and cheek underwent tumor ablation along with a left modified radical neck dissection and tracheostomy. (Figure 1) The exophytic buccal mass measured $6 \times 6 \times 3 \mathrm{~cm}$ from the superior and inferior gingiva-buccal sulcus extending posteriorly to the retromolar trigone along with induration of the oral commissure and cutaneous 
CASE REPORTS

Philippine Journal Of Otolaryngology-Head And Neck Surgery

Vol. 29 No. 1 JANUARY - JUNE 2014

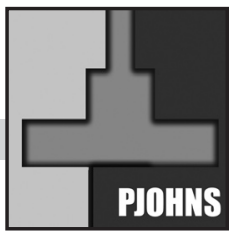

involvement of the cheek. Included with the tumor ablation was a partial parotidectomy and marginal mandibulectomy resulting in a large complex full thickness defect. (Figure 1)

Simultaneous with the neck dissection, two ALT flaps measuring 8 $\times 22 \mathrm{~cm}$ on the left and $6 \times 21 \mathrm{~cm}$ on the right were harvested by two reconstructive surgeons. (Figures 2, 3) The larger left ALT flap was folded and designed to cover both the intraoral and facial / cheek defect with its pedicle anastomosed to the left facial artery and vein. A lip sling was constructed using a strong non-absorbable 2.0 suture from the orbicularis oris muscle of the lower and upper lip through the folded portion of the flap to preserve oral competence. The smaller right ALT flap was utilized to cover the upper cervical soft tissue loss and its vascular pedicle was anastomosed to the ipsilateral superior thyroid artery and facial vein. Vacuum drains and nasogastric tube were later inserted, and the donor-sites were closed primarily without needing skin grafting. (Figure 4) The entire procedure lasted 14 hours.

The immediate postoperative period was fairly unremarkable. Neck swelling and minimal flap venous congestion was noted on the second postoperative day that resolved spontaneously on the succeeding day. Ambulation was allowed on the first postoperative day and the patient was decannulated on the fourth postoperative day. Good function and aesthetic satisfaction were reported by the patient in the first postoperative week and oral diet was resumed progressively. (Figure 5) The donor sites had a $1 \times 4 \mathrm{~cm}$ dehiscence that was managed conservatively with wound debridement and healed spontaneously by secondary intention resulting in a linear scar. The patient was discharged on the ninth postoperative day and advised adjuvant chemotherapy and radiation therapy following multi-disciplinary consultation with the oncology services. The upper ALT flap was over-corrected in size as atrophy was anticipated following adjuvant radiation while a secondstage lip reconstruction is planned following full oncologic treatment. (Figure 6)

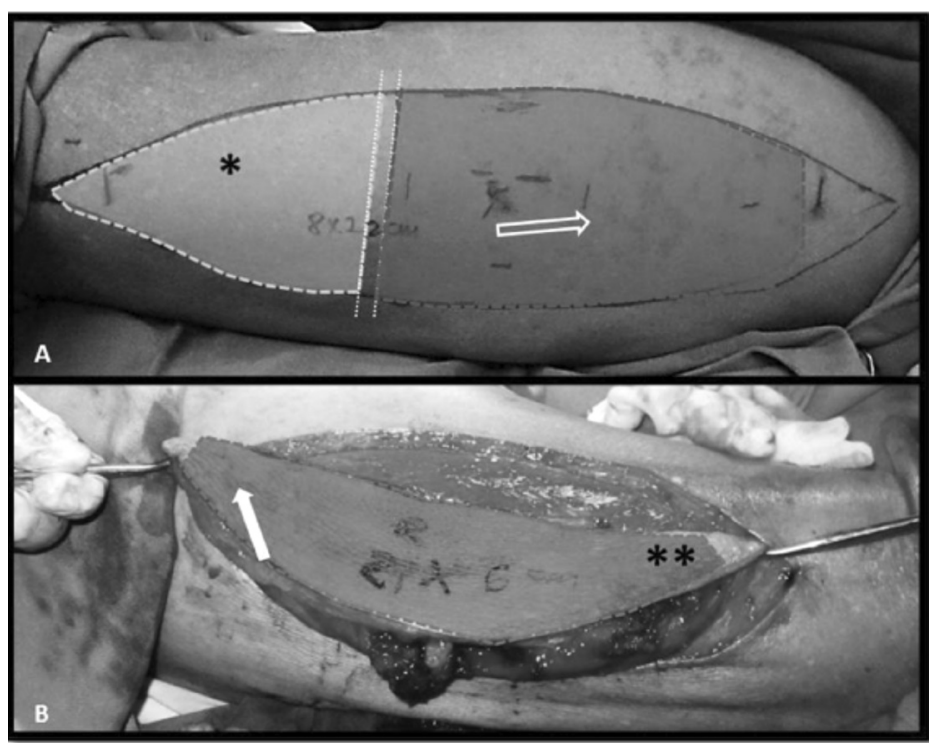

Figure 2. Two ALT Flap Design A. ALT flap harvested from the left thigh measuring $8 \times 22 \mathrm{~cm}$ for closure of the upper extent of the defect(*) The thin and most distal portion of the flap was used for intraoral defect closure, and was folded (broken lines) as the distal portion of the flap (open arrow) was used for closure of the external cheek defect. B. Right ALT flap showing distal $\left({ }^{* *}\right)$ and proximal(bold arrow) portions, measuring $6 \times 21 \mathrm{~cm}$ was used to close the lower cervical defect.

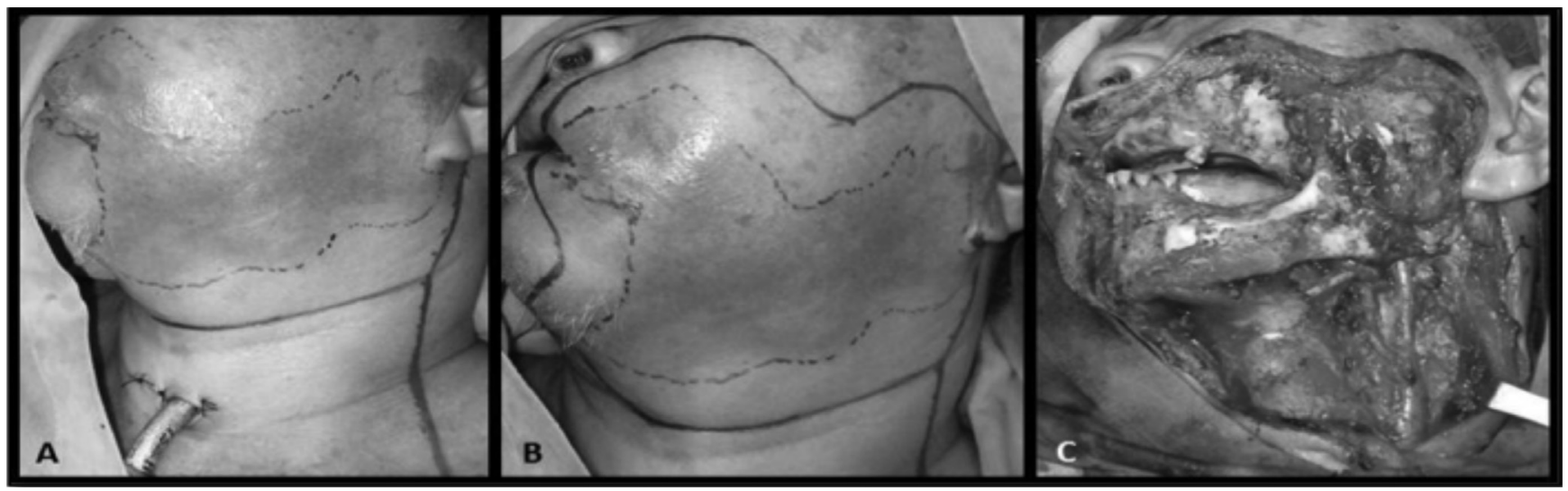

Figure 1. Topographic tumor extent, surgical margins and resultant defect. A. Stage IVA (T4aN2cM0) squamous cell carcinoma of the buccal cavity with cutaneous invasion. Skin markings of tumor induration and planned neck incisions. B. Markings of the $2 \mathrm{~cm}$ tumor margins incorporating the lower border of resection with the horizontal and upper vertical cervical incisions to prevent cervical flap necrosis. C. Resultant complex defect of the oral cavity, cheek and neck regions following tumor ablation, marginal mandibulectomy, upper alveolar resection, partial parotidectomy, and MRND. Intraoperatively, tumor invasion extended caudally from the left lateral lip commissure, superiorly to the uppermost alveolar and buccal junction, posteriorly to the retromolar region inferiorly to the mandibular alveolus, and anteriorly invading the masseter muscles, parotid and cutaneous area of the cheek and submandibular area. 


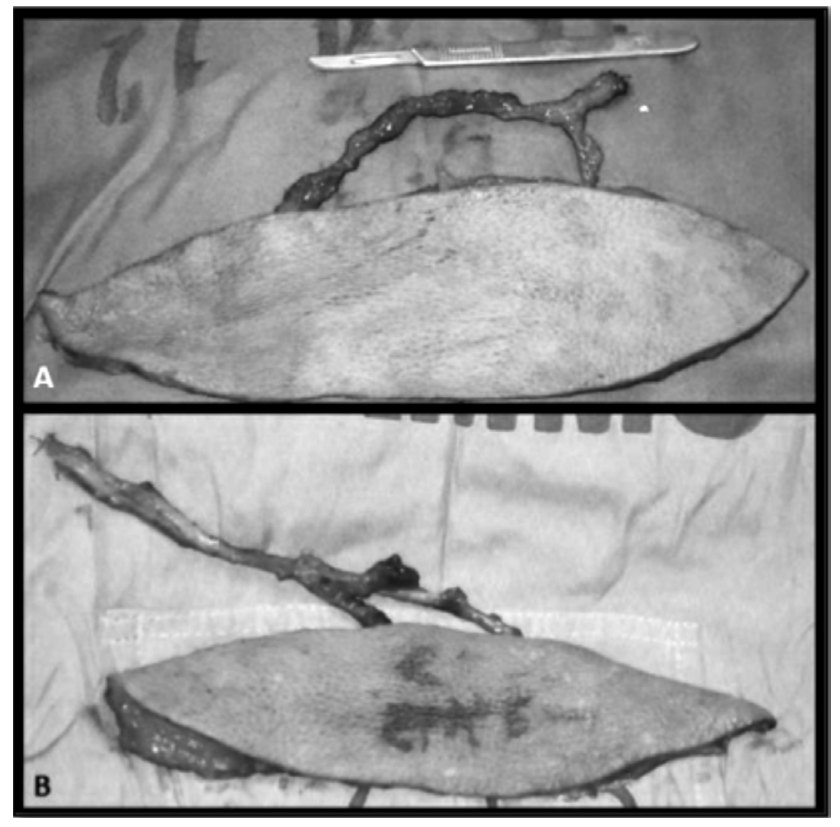

Figure 3. Harvested ALT Flaps. A. Right ALT flap which measured $8 \times 22 \mathrm{~cm}$, B. Left ALT flap which measured $6 \times 21$

\section{DISCUSSION}

The anterolateral thigh (ALT) free flap has gained popularity since its introduction by Song et al. in 1984. ${ }^{1}$ Its blood supply is from the perforators of the descending branch of the lateral circumflex femoral artery. In 2008, Ramos et al. reported ALT reconstruction of a throughand-through defect of the buccal mucosa and cheek that healed uneventfully. ${ }^{2}$ Since then, the use of ALT for reconstruction of head and neck defects in the Philippines has increased because of its inherent versatility. The shortened operation time of 14 hours in our case was due to a simultaneous surgical team management comprised of as the head and neck ablative team and the reconstruction team.

With a combined defect of $20 \times 25 \mathrm{~cm}$ on the cheek and cervical area of our patient, various flaps were considered. (Table 1) The pectoralis major myocutaneous flap (PMMF) which is considered for decades as the work-horse pedicled flap for head and neck reconstruction was excluded mainly because it lacks soft tissue coverage. Other disadvantages that limits its use were unaesthetic supraclavicular bulge, chest wall deformity, short act of rotation for more cephalad defects and resulting restriction in neck motion. ${ }^{3}$

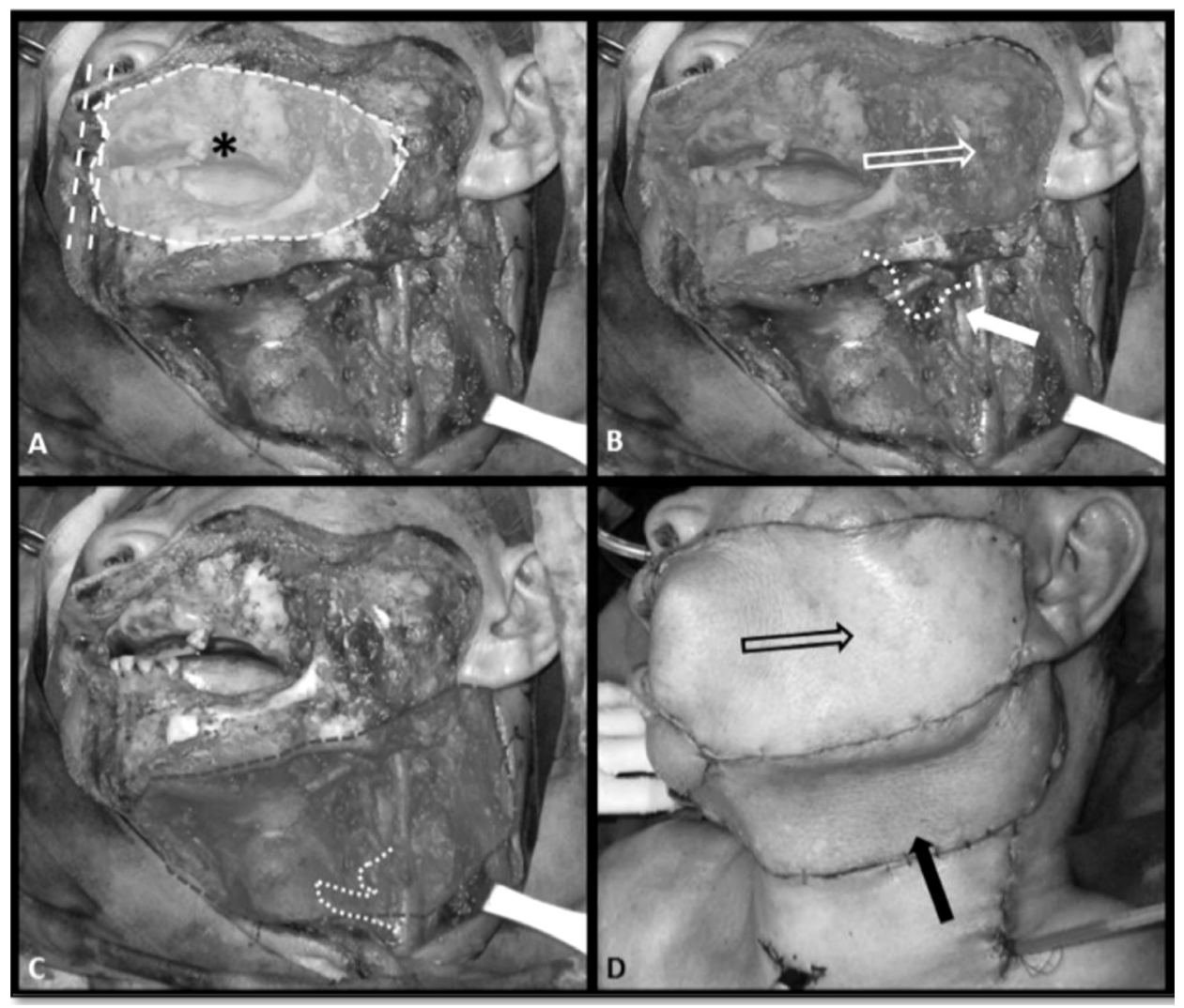

Figure 4. Defect closure using the 2 ALT flaps. A. The intraoral defect closure with the thin distal portion of the 1st ALT flap $\left({ }^{*}\right)$, folded (broken lines) at the lip commissure and internally suturing the upper and lower orbicularis oris to preserve oral continence. B. Closure of the external facial defect with the remaining portion of the 1st ALT flap (open arrow). Also illustrated is the course of the pedicle anastomosis to the facial artery and vein (broken line). C. the 2nd ALT flap harvested from the right thigh used for the rest of the cervical defect. Also illustrated is the course of the vascular pedicle anastomosed to the superior thyroid artery and facial vein (broken line). D. The resultant 2 -flap closure of the large complex defect showing the right (bold arrow) and the left (open arrow) ALT flaps. 


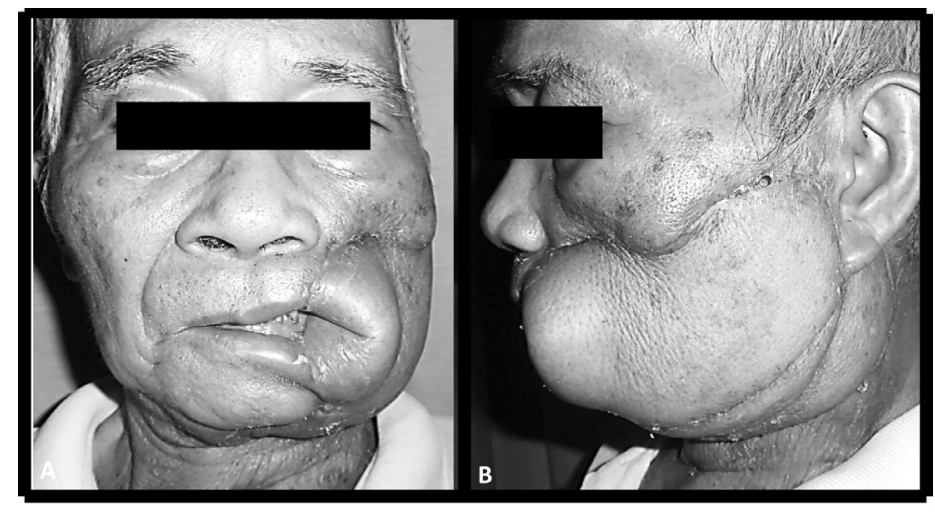

Figure 5. Post-operative Profile of the Patient. A. The patient on mouth opening showing the bulky folded portion of the 1st ALT flap, 1 month post-operatively. The flap was over-corrected in size anticipating atrophy after radiation treatment. B. Side profile of patient showing good color aesthetic match coinciding the aesthetic zone of the cheek, with overlap of the preauricular and buccomandibular zones.

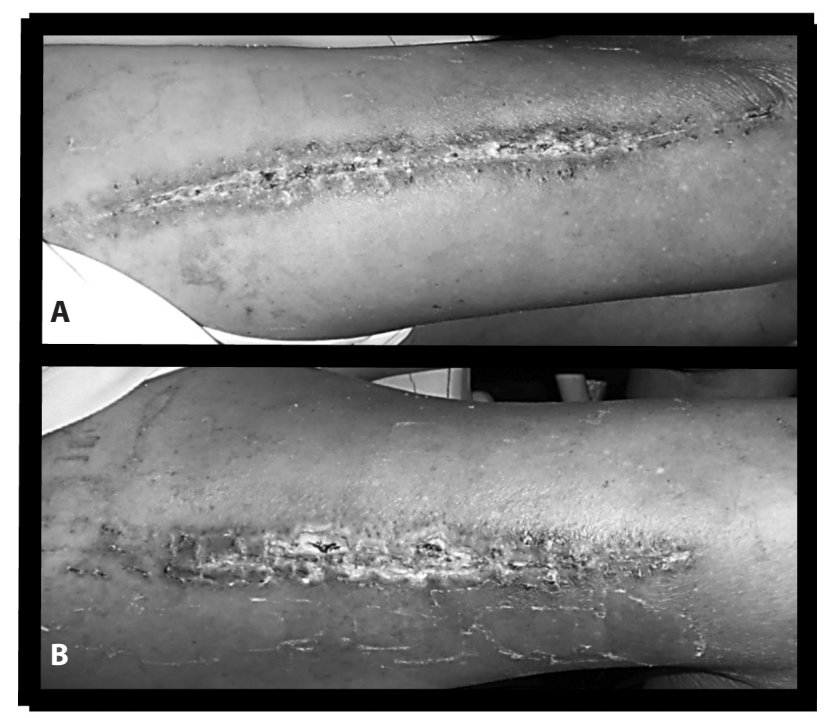

Figure 6. Post-operative anterior thigh. A. The left (top) and B. right (bottom) anterior thighs of the patient one month post-operatively. Even with dehiscence, both thighs had minimal morbidity and healing with secondary intention.

Other flaps considered were the trapezius flap, latissimus dorsi free flap and the radial forearm free flap. All have been known of their vast applications for head and neck reconstruction but as with the PMMF, are mainly limited by deficient tissue coverage in relation to resultant defect in our patient, Utilizing double ALT flaps then established our goals of reconstructing the large complex full thickness defect; preserving oral cavity functions and providing an option with the least donor site morbidity and a fairly acceptable aesthetic outcome.
Table 1. Alternative flaps for closing a large Head and Neck Defect

\begin{tabular}{|l|l|l|}
\multicolumn{1}{c|}{ Flap } & \multicolumn{1}{|c|}{ Description } & \multicolumn{1}{c|}{ Disadvantage } \\
\hline $\begin{array}{l}\text { Pectoralis Major } \\
\text { Myocutaneous Flap } \\
\text { (PMMF) }\end{array}$ & $\begin{array}{l}\text { "Work-horse" pedicled } \\
\text { flap for head and neck } \\
\text { reconstruction. } \\
\text { Vascular supply: } \\
\text { Thoracoacromial arety } \\
\text { Skin paddle surface area } \\
26 \times 16 \mathrm{~cm}\end{array}$ & $\begin{array}{l}\text { Bulky flap, } \\
\text { Postoperative stenosis } \\
\text { Unaesthetic supraclavic- } \\
\text { ular bulge and chest wall } \\
\text { deformity; } \\
\text { Fistula problems } \\
\text { Short arc of rotation } \\
\text { Restricted neck motion }\end{array}$ \\
\hline Latissimus Dorsi Free & $\begin{array}{l}\text { Large surface area of } 20 \\
\text { x 35cm } \\
\text { Vascular supply: }\end{array}$ & $\begin{array}{l}\text { Intraoperative reposi- } \\
\text { tioning and donor site } \\
\text { Thorbidity, shoulder dys- } \\
\text { Thoracodorsal artery } \\
\text { function }\end{array}$ \\
\hline $\begin{array}{l}\text { Radial Forearm Free } \\
\text { Flap (RF) }\end{array}$ & $\begin{array}{l}\text { From volar surface of } \\
\text { forearm } \\
\text { Thin and pliable with a } \\
\text { dimension of } 13 \times 12 \mathrm{~cm} \\
\text { Vascular supply: Radial } \\
\text { artery, Cephalic vein or } \\
\text { venae commitantes }\end{array}$ & $\begin{array}{l}\text { Donor site morbidity: } \\
\text { tendon exposure, sac- } \\
\text { rificial of blood supply, } \\
\text { unsightly scar. } \\
\text { Hand stiffness, pain and } \\
\text { anesthesia / paresthesia }\end{array}$ \\
\hline
\end{tabular}

The ALT flap is a reliable and versatile option for head and neck reconstruction with reported size ranging from $12-35 \mathrm{~cm}$ in length and 4-11 cm in width. ${ }^{6}$ In our experience, the resultant complex defect that measured $20 \times 25 \mathrm{~cm}$ may not be adequately reconstructed with a single ALT flap nor other type of soft-tissue flaps. Moreover, harvesting larger soft tissue flaps may already necessitate additional skin grafting and add up to possible donor-site complications. ${ }^{7}$ The utilization of two ALT flaps enabled the primary reconstruction of the complex defect minimal morbidity, shorter operating time and shorter hospital stay.

\section{REFERENCES}

1. Song YG, Chen GZ, Song YL, The free thigh flap: a new free flap concept based on the septocutaneous artery, Br J Plast Surg 1984, 37(2) 149-59.

2. Ramos RM, Castañeda SS, Alonzo DM; Anterolateral Thigh Flap Reconstruction of Full Thickness Buccal Defect; Philipp J Otolaryngol Head Neck Surg 2008 Jan-Jun;23(1):28-30.

3. Yang JY, Rosen MR, Keane WM, Flaps and Grafts in the Head and Neck edited by Snow JB Jr, Ballenger JJ, Ballenger's Otorhinolaryngology Head and Neck Surgery $16^{\text {th }}$ edition 2003 Spain; BC Decker Inc, , 972-94.

4. Camaioni A, Loreti A, Damini V, Bellion M, Passali FM, Viti C; Anterolateral thigh cutaneous flap vs. radial forearm free flap in oral and oropharyngeal reconstruction: an analysis of 48 flaps Acta Otorhinolaryngol Ital 2008;28: 7-12.

5. Farace F, Fois VE, Manconi A, Puddu A, Stomeo F, Tullio A, Meloni F, et al. Free anterolateral thigh flap versus free forearm flap: Functional results in oral reconstruction. $J$ Plast Reconstr Aesthet Surg. 2007;60(6):583 -7.

6. Di Candia M, Lie K, Kumiponjera D, Simcock J, Cormack GC, Malata CM; Versatility of the anterolateral thigh flap: the four seasons flap; Eplasty 2012; 12: e21.

7. Kimata Y, Uchiyama K, Ebihara S, Sakuraba M, lida H, Nakatsuka T, Harii K, Anterolateral thigh flap donor-site complications and morbidity. Plast Reconstr Surg 2000 Sep;106(3):584-9. 